\title{
Analisis Perencanaan Persediaan Untuk Meningkatkan Pengendalian Biaya Produksi Pada Mebel Tenang Jaya
}

\author{
Devi Lestari Pramita Putri ${ }^{1}$, Citra Larashati Surya ${ }^{2}$ \\ ${ }^{1}$ Universitas Madura \\ devi_permai@yahoo.co.id \\ ${ }^{2}$ Universitas Madura \\ citra.larashati.surya@gmail.com
}

\begin{tabular}{ccc}
\hline Diterima & Direvisi & Disetujui \\
$16-01-2020$ & $28-01-2020$ & $31-01-2020$ \\
\hline
\end{tabular}

\begin{abstract}
Abstrak - Mebel Tenang Jaya Adalah bisnis yang bergerak di bidang furniture. Bahan baku yang digunakan adalah kayu jati, dalam kelncaran proses produksi, maka perusahaan harus menyediakan bahan baku yang cukup agar tidak mengalami kelebihan atau kekurangan bahan baku. Metode penelitian yang digunakan adalah deskriptif kuantitatifadalah data yang berbentuk angka-angka, teknik pengumpulan data yang digunakan adalah wawancara dan dokumentasi. Teknik analisis data yang digunakan dalam penelitian ini adalah dengan langkah (1) Data produksi (2) Menentukan Lead time (3) Menentukan Safety Stock (4) Menentukan Re-order Point (5) Menghitung jumlah pemeblian barang yang paling ekonomis dengan metode Economic Order Quantity (6) Menentukan Total Cost (7) Menentukan Persediaan Maksimal (8) menentukan frekuensi pemesanan (9) Membuat gambar grafik / kurva untuk mengukur posisi Safety Stock, Re-order Point(ROP) dan Economic Order Quantity (EOQ) agar tampak lebih jelas hasil analisisnya. Hasil penelitian menunjukkan bahwa pada tahun 2017 Lead Time adalah Rp. 16.159.500. Safety Stock adalah Rp. 17.955.000. Re-Order Point Rp. 34.114.500. Economic Order Quantity 3.870. biaya pesanana 9.250.000 dan penyimpanan Rp7.770.000. Maximal Stock 17.958.870. Frekuensi pemesanan sebanyak 5 kali. Pada tahun 2018 lead time adalah Rp. 19.563.600 Safety Stock Rp. 23.273.997. Re-Order Point sebanyak Rp. 42.927.597. Economic Order Quantity 4.152 Biaya Pemesanan Rp 10.000.000 dan penyimpanan Rp. 10.200.000. Maximal Stock Rp23.278.149 Frekuensi pemesanan sebanyak 5 kali. Dengan menggunakan metode Economic Order Quantity pada mebel Tenang Jaya dapat mengifisiensi biaya produksi
\end{abstract}

Kata Kunci: Perencanaan Persediaan, Pengendalian Biaya Produksi

\begin{abstract}
Furniture Tenang Jaya Is a business that is engaged in furniture. The raw material used is teak wood, in a smooth production process, the company must provide sufficient raw material so that they do not experience excess or lack of raw material. The research method used is descriptive quantitative data in the form of numbers, Data collection techniques used were interviews and documentation. Data analysis techniques used in this study are by step (1) Production data (2) Determine Lead time (3) Determine Safety Stock (4) Determine Re-order Point (5) Calculated the most economical amount of goods purchased using the Economic Method Order Quantity (6) Determine Total Cost (7) Determine maximum Stock Maximum Stock (8) Determine Order Frequency (9) Make a graphic image / curve to measure Safety Stock, Reorder Point (ROP), and Economic Order Quantity (EOQ) positions so the results of the analysis are clear. The result showed that in 2017 Lead Time was IDR 16.159.500. Safety Stock is IDR 17.955.000. Re-order Points as much as IDR 34.114.500. Economic Order Quantity 3.870. The booking IDR 9.250.000 and the storage IDR 7.770.000. IDR 17.958.870. maximal stock the order frequency is 5 times. In 2018 the lead time was Idr 19.563.600 Safety Stock was IDR 23.273.997. Re-orde Points as much as IDR 42.927.597. Economic Order Quantity 4.152 The booking Rp 10.000.000 and the storage Rp. 10.200.000. Maximal stock of IDR 23.278.149 The order frequency is 5 imes. By using the economic order quantity method in Tenang Jaya Furniture, it can streamline production costs.
\end{abstract}

Keyword: Inventory Planning, Controlling Production Cost

\section{PENDAHULUAN}

Globalisasi saat ini sudah sangat popular di kalangan masyarakat dan di seluruh dunia sehingga menyebabkan perdagangaan saat ini semakin bebas dan persaingan antar perusahaan semakin kuat. 
Dengan adanya globalisasi perusahaan diharapkan dapat mengubah tantangan peluang menuju kesuksesan dan memiliki daya saing tinggi sehingga mampu bertahan dan dapat memenangkan persaingan global. Untuk dapat memenangkan persaingan tersebut, maka perusahaan harus bisa melakukan perubahan-perubahan yang mendorong aktifitas usaha untuk melakukan pengawasan persediaan dan efisiensi biaya, sehingga mereka dapat menekan biaya untuk mendukung profit yang semakin menurun seperti dengan melakukan efektifitas persediaan barang dalam suatu perusahaan.

Persediaan (inventory) merupakan elemenelemen aktiva lancar yang selalu dianggap likuid dibandingkan dengan elemen-elemen aktiva yang lain. Inventory dianggap sangat penting bagi perusahaan, khususnya dibidang industri dan perdagangan, selain itu persediaan juga mempunyai pengaruh pada fungsi bisnis terutama fungsi operasi pemasaran dan keuangan dan persediaan juga merupakan kekayaan perusahaan yang memiliki peranan penting dalam operasional pabrik (manufacturing), sehingga harus dilakukan perencanaan dan pengendalian untuk efisiensi biaya persediaan.

Perencanaan adalah kegiatan yang dilakukan oleh setiap perusahaan, baik perusahaan besar maupun perusahaan kecil, untuk berhasil (sukses) nya perusahaan mencapai tujuan (Assauri, 2008). Di dalam perencanaan kita harus memperhitungkan berbagai kondisi yang terjadi di perusahaan dan juga harus saling berhubungan untuk memperbaiki profitabilitas perusahaan dengan menentukan terlebih dahulu apa yang harus dilakukan, bagaimana harus dilaksanakan, kapan dan bagaimana alternatif untuk mencapai tujuan, termasuk biaya-biaya yang akan terjadi juga harus diukur. Tujuan Perencanaan adalah untuk mengetahui berapa besar jumlah persediaan yang harus dipesan, sehingga persediaan tidak akan melebihi kapasitas dan perusahaan dapat meminimalkan biaya-biaya persediaan sehingga perusahaan dapat bekerja secara efisien. Dalam sistem perencanaan persediaan yang penting yaitu menentukan jumlah pesanan data pembelian yang paling ekonomis dimana biaya persediaan relatif lebih kecil dan menentukan besarnya pesanan pembelian agar tidak terjadi kelebihan stok maupun kekurangan stok.

Tindakan yang harus dilakukan manajemen adalah pengendalian gunanya untuk memperbesar kemungkinan dalam pencapaian sasaran yang telah ditetapkan perencanaan dan juga untuk memastikan bahwa seluruh bagian organisasi berfungsi seutuhnya. Pencapaian tujuan perusahaan dalam memaksimalkan nilai adalah melakukan pengendalian persediaan yang berhubungan dengan harga pokok produksi yaitu menekan biaya produksi yang akan terjadi. Tujuan dari pengendalian persediaan adalah membantu perusahaan agar tidak sampai kehabisan bahan baku sehingga proses produksi tidak terhenti, mengontrol persediaan agar tidak terlalu menumpuk digudang sehingga dapat mengurangi biaya-biaya yang tidak diinginkan.

Fungsi pengendalian persediaan adalah jika jangka waktu pengiriman bahan baku relatif lama, maka perusahaan perlu menyediakan persediaan bahan baku yang cukup untuk memenuhi kebutuhan operasi perusahaan sampai batas waktu pengiriman. Apabila permintaan barang sifatnya musiman, sedangkan tingkat produksi setiap saat adalah konstan, maka perusahaan dapat melayani permintaan tersebut dengan membuat tingkat persediaan permintaan. Salah satu faktor penentu dalam harga jual produk adalah informasi biaya produksi, di mana biaya produksi akan berpengaruh terhadap keputusan perusahaan dalam menentukan kualitas dan kuantitas suatu produksi. Selain itu dengan adanya biaya produksi, perusahaan dapat mengetahui produk mana yang akan menghasilkan laba lebih besar dan lebih menguntungkan perusahaan.

Hal penting yang harus dilakukan oleh perusahaan untuk mencapai laba yang maksimal adalah dengan cara efisiensi. Ada beberapa alasan sehingga efisiensi persediaan menjadi sangat penting. Alasan pertama yaitu penyimpanan barang diperlukan perusahaan agar dapat memenuhi pesanan pembeli dalam waktu yang cepat. Jika perusahaan tidak memiliki persediaan barang dan tidak dapat memenuhi pesanan pembeli pada saat yang tepat, maka kemungkinan pembeli akan berpindah ke perusahaan lain. Alasan yang kedua untuk berjaga-jaga pada saat barang di pasar langka. Sehingga perusahaan perlu untuk menyimpannya. Apabila persediaan barang dagangan yang dimiliki perusahaan kurang dari yang dibutuhkan maka proses operasional akan terhambat, Apabila persediaan barang dagangan menumpuk di gudang akan mengakibatkan penggunaan dana yang tidak efisien karena tidak banyak modal yang tertanam untuk satu jenis barang saja sehingga dapat meningkatkan biaya penyimpanan dan biaya perawatan serta memperbesar risiko apabila barang tersebut rusak atau hilang.

Economic Order Quantity (EOQ) adalah jumlah pembelian yang paling ekonomis yaitu dengan melakukan pembelian secara teratur sebesar EOQ itu maka perusahaan akan menanggung biayabiaya pengadaan bahan yang minimal (Indriyo, Gitosudarmo, \& Basri, 2002) Metode EOQ adalah pencapaian tingkat persediaan yang seminimum mungkin dengan biaya rendah. Dengan menggunakan metode EOQ suatu perusahaan akan mampu meminimalisir terjadinya out of stock sehingga tidak mengganggu proses produksi dalam perusahaan dan mampu menghemat biaya persediaan karena adanya efisiensi persediaan bahan baku di perusahaan yang bersangkutan. Selain itu 
juga, perusahaan akan mampu mengurangi biaya penyimpanan, penghematan ruang, baik untuk ruangan gudang dan ruangan kerja, menyelesaikan masalah-masalah dari persediaan yang menumpuk sehingga mengurangi resiko yang dapat timbul karena persediaan yang ada digudang. Analisis EOQ ini dapat digunakan dengan mudah dan praktis untuk merencanakan berapa kali suatu bahan dibeli dan dalam kuantitas berapa kali pembelian. Sebagaimana yang dikemukan oleh (Sulaiman, Pengendalian Persediaan Bahan Baku Dengan Menggunakan Metode EOQ Pada UD. Adi Mebel, 2015) jika melakukan perencanaan persediaan bahan baku hanya dengan menggunakan perkiraan, tanpa adanya perencanaan yang tepat, sehingga masalah yang selalu dihadapi oleh perusahaan tersebut aalah biaya yang dikeluarkan baik untuk membeli bahan baku maupun biaya penyimpanan masih tinggi. Berdasarkan hasil pembahasan penelitian terdahulu yang dilakukan pada UD. Adi Mebel dengan menggunakan metode EOQ jumlah pembelian persediaan bahan baku kayu meranti batu, yang paling ekonomis dengan frekuensi pemesanan $4 \mathrm{x}$ dalam satu tahun.

Berdasarkan uraian di atas, penulis melakukan penelitian yang berhubungan dengan Perencanaan persediaan untuk meningkatkan pengendalian biaya produksi, dalam hal ini persediaan bahan baku tahun 2018 di UD Mebel Tenang Jaya.

\section{METODOLOGI PENELITIAN}

1. Tempat dan Waktu Penelitian

Penelitian ini menjadikan Mebel Tenang Jaya sebagai objek penelitian dengan mengmbil data perencanaan bahan baku tahun 2018. Waktu penelitian tahun 2019

\section{Jenis Dan Sumber Data}

Jenis data yang digunakan dalam penelitian ini adalah data kuantitatif. Data kuantitatif adalah data yang berbentuk angka-angka (Sugiyono, 2011) Sumber data yang digunakan dalam penelitian ini adalah data sekunder dan data Primer. Menurut (Suharsimi, 2002) Data sekunder adalah data penelitian yang diperoleh dari dokumen-dokumen grafis (table, catatan, notulen rapat dan lain-lain). Data sekunder umumnya berupa bukti, catatan atas laporan historis yang telah tersusun dalam arsip (data dokumenter) di Toko Mebel Tenang Jaya. Data primer adalah sumber data penelitian yang diperoleh secara langsung dari sumber aslinya yang berupa wawancara dari obyek, dengan kata lain peneliti membutuhkan pengumpulan data dengan cara menjawab pertanyaan riset (metode survei) atau penelitian benda (metode observasi)

3. Metode Pengumpulan Data a. Wawancara (interview)

Merupakan suatu cara untuk mendapatkan data atau informasi dengan melakukan tanya jawab secara langsung pada orang yang mengetahui tentang objek yang diteliti. Dalam hal ini pemilik Mebel Tenang Jaya Waru Barat (HJ. Kusmawati) dan bagian pengiriman (Mohammad Samin).

b. Dokumentasi

Merupakan suatu cara untuk mendapatkan data dengan mempelajari, mengklasifikasi data perusahaan berupa laporan data produksi, laporan pengeluaran dan catatancatatan yang behubungan dengan penelitian.

4. Teknik Analisis Data

Teknik analisis data yang digunakan oleh peneliti dalam penelitian ini adalah analisis kuantitatif, yaitu analisa menggunakan data berupa angkaangka dan rumus-rumus. Ada beberapa rumus yang berhubungan perencanaan dan pengendalian persediaan untuk menganalisa data yang ada. Adapun rumus-rumus tersebut adalah:

a. Menentukan data produksi.

b. Menentukan Lead Time

$$
\mathrm{LT}=\frac{\text { waktu pesan }}{\text { pertahun }} x \text { kebutuhan } B B
$$

c. Menentukan persediaan pengamanan (safety stock)

$$
\mathrm{SS}=\text { LTx } \frac{\text { kebutuhan } B B 1 \text { tahun }}{\text { jml hari dlm } 1 \text { thn }}
$$

d. Menentukan titik pemesanan kembali (Reorder point)

Re-Order Point $(\mathrm{ROP})=\mathrm{LT}+\mathrm{SS}$

e. Menghitung jumlah pembelian barang yang paling ekonomis dengan metode Economic Order Quantity (EOQ)

$$
E O Q=\sqrt{\frac{2 x R x S}{P x i}}
$$

Keterangan:

EOQ = Economic Order Quantity, kuantitas pembelian paling ekonomis

$\mathrm{R}=$ jumlah pembelian bahan baku dalam satu tahun

$\mathrm{S}=$ Biaya pemesanan setiap kali pesan.

$\mathrm{P}=$ Harga beli per unit

$\mathrm{I}=$ Biaya penyimpanan di gudang, yaitu dinyatakan dalam prosentase dari nilai rata-rata persediaan.

\section{f. Menentukan Total Cost}

$T C=C r+C c$ sedangkan $\mathrm{Cr}=\frac{\mathrm{R}}{\mathrm{Q}} x S$ dan $\mathrm{Cc}=\frac{\mathrm{Q}}{2} x P x i$

Keterangan:

$\mathrm{TC}=$ Total biaya (rupiah per tahun)

$\mathrm{Cr}$ = Biaya pemesanan/Cost of reordering (rupiah per tahun)

$\mathrm{Cc}=$ Biaya penyimpanan/Carring cost (rupiah per tahun)

$\mathrm{R}=$ Jumlah kebutuhan barang (per tahun) 
$\mathrm{Q}=$ Jumlah pemesanan (per tahun)

$\mathrm{S}=$ Biaya pemesanan (rupiah per tahun)

$\mathrm{P}=$ Harga per unit barang

I = Biaya penyimpanan dari prosentase nilai ratarata persediaan

g. Menentukan persediaan maksimal (maximal stock)

Maximal Stock $(\mathrm{MS})=$ safety stock $+\mathrm{EOQ}$

h. Frekuensi pemesanan

$$
f=\frac{R}{E O Q}
$$

Keterangan:

$\mathrm{F}=$ Frekuensi

$\mathrm{R}=$ Jumlah kebutuhan barang (per tahun)

EOQ = Economic Order Quantity, kuantitas pembelian optimal yang ekonomis,

i. Membuat gambar grafik/kurva untuk mengukur posisi Safety Stock, Reorder Point (ROP), dan Economic Order Quantity (EOQ) agar tampak jelas hasil analisis.

\section{HASIL DAN PEMBAHASAN}

1. Menentukan data produksi kayu /kubik tahun 2018

Tabel 1. Pengadaan bahan baku Tahun 2018 (Perkubik)

\begin{tabular}{|l|c|c|c|c|c|}
\hline Bulan & $\begin{array}{c}\text { Persedia } \\
\text { an Awal }\end{array}$ & $\begin{array}{c}\text { Bel } \\
\text { i }\end{array}$ & $\begin{array}{c}\text { Jumla } \\
\text { h Beli }\end{array}$ & $\begin{array}{c}\text { Diproduk } \\
\text { si }\end{array}$ & $\begin{array}{c}\text { Sis } \\
\text { a }\end{array}$ \\
\hline Januari & 10 & 14 & 24 & 20 & 4 \\
\hline Februari & 10 & 11 & 21 & 16 & 5 \\
\hline Maret & 12 & 18 & 30 & 27 & 3 \\
\hline April & 15 & 15 & 30 & 27 & 3 \\
\hline Mei & 10 & 26 & 36 & 32 & 4 \\
\hline Juni & 13 & 47 & 60 & 58 & 3 \\
\hline Juli & 15 & 45 & 60 & 59 & 1 \\
\hline Agustus & 8 & 37 & 45 & 40 & 5 \\
\hline $\begin{array}{l}\text { Septemb } \\
\text { er }\end{array}$ & 10 & 32 & 42 & 40 & 2 \\
\hline Oktober & 10 & 16 & 36 & 33 & 3 \\
\hline $\begin{array}{l}\text { Novemb } \\
\text { er }\end{array}$ & 12 & 14 & 36 & 34 & 2 \\
\hline $\begin{array}{l}\text { Desembe } \\
\text { r }\end{array}$ & 5 & 9 & 11 & 9 & 2 \\
\hline Jumlah & 128 & 28 & 431 & 395 & 36 \\
\hline
\end{tabular}

Sumber : Laporan Barang Mebel Tenang Jaya (2018)

\section{Menentukan Lead Time}

Jangka waktu dalam proses pembelian bahan baku kayu jati yang dilakukan mebel Tenang Jaya selama 7 hari dari daerah balisampai ke madura.

Lead Time $=\frac{\text { waktu pemesanan }}{\text { per tahun }} \times$ Kebutuhan Bahan Ba

$$
=\frac{7}{360} \times 431
$$

$$
\begin{aligned}
& =0,019 \times 431 \\
& =8,1
\end{aligned}
$$

3. Menentukan safety stock

Persediaan pengamanan merupakan suatu persediaan yang dicadangkan sebagai pengaman dari kelangsungan proses produksi perusahaan. persediaan pengaman diperlukan karena dalam kenyataannya jumlah bahan baku yang diperlukan dalam proses produksi tidak selalu tepat sseperti yang direncanakan oleh perusahaan. Maka dari itu perusahaan perlu mengetahui persediaan pengaman agar nantinya perusahaan tidak mengalami kekurangan barang (stock out) yang nantinya dapat mengganggu proses produksi.

Safety Stock (SS) $=$ Lead Time $x \frac{\text { kebutuhan bahan baku } 1 \text { tahun }}{\text { Jumlah hari efektif dalam } 1 \text { tahun }}$

$$
\begin{aligned}
& =8,1 \times \frac{431}{360} \\
& =8,1 \times 1,2 \\
& =9,8
\end{aligned}
$$

4. Menentukan titik pemesanan kembali (Re-order point) merupakan sustu titik dimana mebel Tenang Jaya harus melakukan pemesanan bahan baku sehingga persediaan yang dilakukan dapat diterima tepat pada waktunya sehubungan dengan adanya safety stock dan lead time.

$$
\begin{aligned}
\text { Re-Order Point }(\mathrm{ROP}) & =\text { lead time }+ \text { safety stock } \\
& =8,1+9,8 \\
& =18 \mathrm{kubik}
\end{aligned}
$$

5. Menghitung jumlah pembelian yang paling ekonomis dengan metode Economic Order Quantity (EOQ) Mebel menentukan jumlah bahan baku kayu jati harus didasarkan pada pertimbangan efisiensi yang disebut Economic Order Quantity (EOQ) hal ini bertujuan agar biaya-biaya yang timbul di dalam pengadaan persediaan dapat ditekan seminimal mungkin. Besarnya EOQ dapat ditentukan dengan menggunakan rumus sebagai berikut:

$$
E O Q=\sqrt{\frac{2 x R x S}{P x i}}
$$

Keterangan:

EOQ = Economic Order Quantity, kuantitas pembelian paling ekonomis

$\mathrm{R}=$ jumlah pembelian bahan baku dalam satu tahun

$\mathrm{S}=$ Biaya pemesanan setiap kali pesan.

$\mathrm{P}=$ Harga beli per unit

$\underline{\underline{u}}$ Biaya penyimpanan di gudang, yaitu dinyatakan dalam prosentase dari nilai rata-rata persediaan.

Dengan rumus Economic Order Quamtity (EOQ) dapat diketahui tingkat pemesanan yang 
paling ekonomis pada persediaan bahan baku kayu jati pada tahun 2018:

a. Kebutuhan bahan baku kayu jati dalam 1 tahun 431 kubik

b. Biaya pemesanan yang terdiri dari biaya transportasi Rp. 2.000.000

c. Harga bahan baku Rp. 2.400 .000

$$
\begin{aligned}
& E O Q=\sqrt{\frac{2 x R x S}{P x i}} \\
& =\sqrt{\frac{2 x 431 x R p \cdot 2.000 .000}{R p \cdot 2.400 .000 x 10 \%}} \\
& =\sqrt{\frac{R p \cdot 1.724 .000 .000}{R p \cdot 240.000}} \\
& =\sqrt{7.183,3333333333} \\
& =84,7545475673
\end{aligned}
$$

Menentukan Total Cost

Biaya total merupakan jumlah jumlah keseluruhan biaya tetap dan variable yang dikeluarkan perusahaan untuk mengahsilkan sejumlah produk dalam satu periode tertentu.

$T C=C r+C c$ sedangkan $\mathrm{Cr}=\frac{\mathrm{R}}{\mathrm{Q}} x S$ dan $\mathrm{Cc}=\frac{\mathrm{Q}}{2} x P x i$

Keterangan:

$\mathrm{TC}=$ Total biaya (rupiah per tahun)

$\mathrm{Cr}=$ Biaya pemesanan/Cost of reordering (rupiah per tahun)

$\mathrm{Cc}=$ Biaya penyimpanan/Carring cost (rupiah per tahun)

$\mathrm{R}=$ Jumlah kebutuhan barang (per tahun)

$\mathrm{Q}=$ Jumlah pemesanan (per tahun)

$\mathrm{S}=$ Biaya pemesanan (rupiah per tahun)

$\mathrm{P}=$ Harga per unit barang

$\mathrm{I}=$ Biaya penyimpanan dari prosentase nilai rata-rata persediaan.

Biaya pemesanan yang ditanggung mebel Tenang Jaya dengan jumlah kebutuhan bahan baku kayu jati sebagai berikut:

$$
\begin{aligned}
& \mathrm{Cr}=\frac{431}{85} \times R p .2 .000 .000 \\
& =5 \text { x Rp. } 2.000 .000 \\
& =\text { Rp. } 10.000 .000
\end{aligned}
$$

Biaya penyimpanan yang ditanggung mebel Tenang Jaya dengan jumlah kebutuhan bahan baku kayu jati sebagai berikut:

$$
\begin{aligned}
\mathrm{Cc} & =\frac{\mathrm{Q}}{2} x P x i \\
& =\frac{85}{2} x R p .2 .400 .000 \times 10 \% \\
& =42,5 \times \mathrm{Rp} .2 .400 .000 \times 10 \% \\
& =\mathrm{Rp} .10 .200 .000
\end{aligned}
$$

Perhitungan jumlah keseluruhan yang harus dikeluarkan oleh mebel Tenang Jaya berkaitan dengan penyeediaan bahan baku tahun 2018 sebagai berikut:

$\mathrm{Tc}=\mathrm{Cr}+\mathrm{Cc}$

$$
\begin{aligned}
& =\text { Rp. } 10.000 .000+\text { Rp. } 10 \cdot 200.000 \\
& =\text { Rp. } 20.200 .000
\end{aligned}
$$

1. Menentukan persediaan maksimal (Maximal Stock)

Maximal Stock (persediaan maksimal) yaitu batas maksimal barang yang akan di produksi atau disediakan mebel Tenang Jaya:

Maximal Stock $(\mathrm{MS})=$ safety stock $+\mathrm{EOQ}$

$$
=9,8+85
$$$$
=94,8 \text { kubik }
$$

2. Menentukan frekuensi pemesanan

$$
f=\frac{R}{E O Q}
$$

Keterangan:

$\mathrm{F}=$ Frekuensi

$\mathrm{R}=$ Jumlah kebutuhan barang (per tahun) $\mathrm{EOQ}=$ Economic Order Quantity, kuantitas pembelian optimal yang ekonomis,

Jumlah frekuensi pemesanan didapat dari jumlah pembelian bahan baku selama satu tahun dibagi dari hasil EOQ, sehingga akan diketahui berapa frekuensi pemesanan bahan baku kayu jati yang ada dimebel Tenang Jaya.

$$
\begin{aligned}
f & =\frac{R}{E O Q} \\
& =\frac{431}{85} \\
& =5 \mathrm{kali}
\end{aligned}
$$

3. Membuat gambar grafik untuk mengukur posisi Safety Stock, Re-Order Point dan Economic Order Quantity.

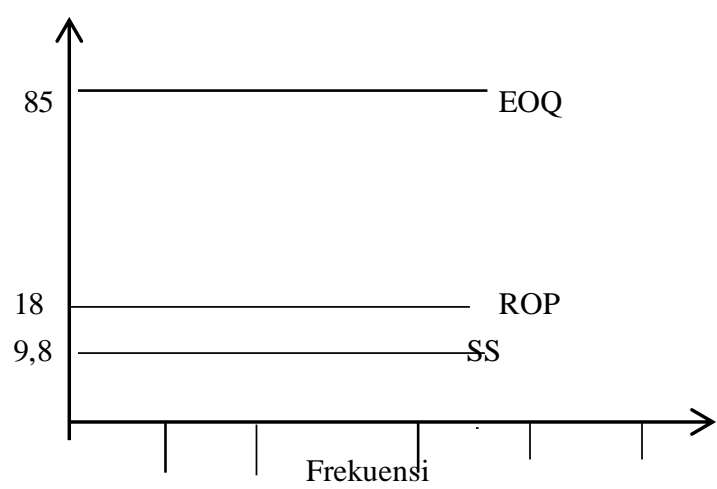

Suber: Mebel Tenang Jaya (2018)

Gambar 1. Grafik posisi EOQ, ROP, SS

Dari grafik diatas di jelaskan bahwa diangka 85 merupakan titik dimana pembelian bahan baku 
paling ekonomis pada mebel Tenang Jaya yang disebut Economic Order Quantity (EOQ), kemudian di angka 18 merupakan titik dimana pemesanan kembali atau Re-Order Point dilakukan oleh mebel Tenang Jaya unruk pemesanan bahan baku sehingga persediaan yang di butuhkan dapat diterima tepat pada waktunya agar proses produksi berjalan dengan lancar, selanjutnya pada angka 9,8 menunjukkan dimana posisi Safety Stock yang terdapat di mebel merupakan suatu persdiaan yang dicadangkan sebagai pengaman dari kelangsungan proses produksi mebel Tenang Jaya. Pesediaan pengaman diperlukan karena dalam kenyataannya jumlah bahan baku yang diperlukan untuk proses produksi tidak selalu tepat seperti yang direncanakan oleh mebel. Hal ini berguna untuk mengantisipasi terjadinya kenaikan pemesanan dalam mebel sehingga dengan adanya Safety Stock ini perusahaan dapan mengatasi kemungkinan terjadinya kenaikan pesanan dan juga mebel tidak mengalami kekurangan barang (stock out) yang nantinya dapat mengganggu proses produksi.

\section{KESIMPULAN}

Berdasarkan hasil penelitian dan pembahasan mengenai perencanaan persediaan dalam meningkatkan pengendalian biaya produksi pada Mebel Tenang Jaya maka dapat ditarik kesimpulan sebagai berikut :

Perencanaan persediaan bahan baku kayu jati mebel Tenang Jaya tahun 2018 adalah 431 kubik. Dan diketahui persediaan yang minimum atau Economic Order Quantity (EOQ) sebanyak 85 kubik. Persediaan pengaman atau Safety Stock bahan baku kayu jati adalah 9,8 kubik, sedangkan persediaan maksimal atau Maximal Stock sebanyak 94,8 kubik.
Dalam Re-Order Point yaitu untuk mengetahui suatu tingkat persediaan saat perusahaan segera melakukan pemesanan bahan baku kayu jati. Hal ini bertujuan untuk mengisi kembali bahan baku yang telah digunakan dalam proses produksi agar kelancaran proses produksi terjamin dan tidak kekurangan bahan baku atau bahkan kehabisan bahan baku. Sehingga persediaan akhir bahan baku yang ada di gudang paling optimal sebanyak 18 kubik. Biaya pemesanan yang akan ditanggung oleh mebel sebesar Rp.10.000.000 sedangkan biaya penyimpanan yang akan ditanggung sebesar Rp.10.200.000, sehingga total biaya persediaan bahan baku di gudang pada tahun 2018 yang ditanggung mebel Rp.20.200.000 dengan menggunakan metode Economic Order Quantity pada Mebel Tenang Jaya dapat mengefisiensikan biaya persediaan

\section{REFERENSI}

Assauri, S. (2008). Manajemen Produksi Dan operasi. Jakarta: UP FE UI.

Indriyo, Gitosudarmo, \& Basri. (2002). Manajemen Keuangan. Yogyakarta: BPFE.

Sugiyono. (2011). Metode Penenlitian Kuantitatif, Kualitatif dan $R \& D$. Bandung: Alfabeta.

Suharsimi, A. (2002). Prosedur Penelitian. Yogyakarta: Rineka Cipta.

Sulaiman , F. (2015). Pengendalian Persediaan Bahan Baku Dengan Menggunakan Metode EOQ Pada UD. A 